\title{
Unit of Electric Capacitance
}

National Cancer Institute

\section{Source}

National Cancer Institute. Unit of Electric Capacitance. NCI Thesaurus. Code C67320.

A unit for measurement of capacity to store an electric charge. 